\title{
Desenvolvimento de Produtos no Contexto das Cadeias de Suprimentos do Setor Automobilístico
}

\section{Product Development in the Context of the Automotive Industry Supply Chains}

\author{
Aline Lamon Cerra* \\ Pós-Doutoranda em Engenharia de Produção pela DEP- UFSCar, \\ São Carlos/SP, Brasil. \\ Jonas Lucio Maia \\ Doutorando em Engenharia de Produção pelo DEP- UFSCar, \\ São Carlos/SP, Brasil.
}

*Endereço: UFSCar - Rodovia Washington Luis, (SP-310) km 235, Monjolinho, São Carlos/ SP, 13565-905.E-mail: alinelc@ terra.com.br 


\title{
Resumo
}

$\mathrm{Na}$ indústria automobilística brasileira, as atividades de Desenvolvimento de Produtos (DP) vêm sendo influenciadas por alterações nas cadeias de suprimentos resultantes da instalação de novas montadoras e da consolidação e desnacionalização do setor de autopeças, bem como do impacto de fenômenos específicos do cenário brasileiro, como a utilização dos motores de 1000cc e bicombustíveis. Este trabalho tem por objetivo comparar os graus de autonomia tecnológica conquistados por três montadoras de motores instaladas no Brasil, bem como identificar as atividades de Desenvolvimento de Produtos que essas subsidiárias realizam em conjunto com os fornecedores. Desse modo, buscamos verificar como são as relações entre empresas dentro de cadeias de suprimentos, como as atividades e competências em DP estão distribuídas ao longo delas e como as montadoras administram essa distribuição. Em geral, as estratégias de DP dessas montadoras são muito semelhantes e orientadas para a competitividade local. As diferenças ocorrem em função das estruturas de suas cadeias de fornecedores e de suas políticas de suprimentos.

Palavras-chave: desenvolvimento de produtos; gestão da cadeia de suprimentos; indústria automobilística.

\begin{abstract}
In the Brazilian Automotive Industry, the Product Development activities have been influenced by changes on supply chains resulting from the investments made by new assemblers in order to install new assembly plants in the country, consolidation and denationalization of the auto-part industry, as well as the impacts of phenomena specific to the Brazilian scenario like the $1000 \mathrm{cc}$ and bi-fuelled engines. This work aims at comparing the degree of technological autonomy conquered by the engine assemblers installed in Brazil, as well as analysing the Product Development activities that those branches accomplish together with their suppliers. In this sense we try to verify how the relationships between the companies inside these chains are, how the Product Development activities and competencies are distributed along them, and how it is managed by the assemblers. Generally, the Product Development activities of these assemblers are very similar and oriented to local competitiveness. The differences take place as a result of their supply chain structures and of their supplying policies.
\end{abstract}

Key words: product development; supply chain management; automotive industry. 


\section{INTRODUÇÃO}

Segundo Salerno, Marx e Zilbovicius (2003), a indústria automobilística mundial tem passado por um processo de importantes transformações que vão além da adição da filosofia e das práticas abarcadas pela 'produção enxuta'. Resumidamente, essas mudanças ocorrem em três grandes áreas: reestruturação interna da produção, através das adoções das práticas enxutas; configuração de novas relações de fornecimento, devido à formação dos blocos de comércio regionais e à introdução de novos arranjos organizacionais (modular, condomínio industrial etc.) e mudanças nas atividades de projeto de produto, através das tecnologias $\mathrm{CAD} / \mathrm{CAM} / \mathrm{CAE}$ e da introdução do conceito de carro mundial.

Novos investimentos em mercados emergentes se tornaram estratégicos não somente para as montadoras, mas também para os fornecedores e para as filiais de empresas transnacionais. Como conseqüência, o setor automotivo desses países tem sofrido alterações estruturais, no que tange ao número e tamanho das empresas dentro do setor e ao padrão de relacionamento que ocorre entre elas.

No Brasil, com a abertura da economia, a partir de 1990, a indústria automobilística passou por uma reestruturação importante, quando diversas montadoras instalaram unidades produtivas em regiões sem tradição no setor automobilístico. Nesse período, as montadoras de automóveis experimentaram um processo de crescimento e investimento, enquanto o setor de autopeças atravessava um período de consolidação e desnacionalização (Posthuma, 1997).

O aumento da concorrência no mercado brasileiro, a partir da década de 90, atraiu investimentos também no segmento de motores para automóveis, especialmente no segmento de baixa cilindrada (para os carros ditos populares).

Estudos revelam que os esforços das empresas do setor automobilístico brasileiro estão fortemente direcionados para Desenvolvimento de Produtos (DP), mas pouco contribuem com o avanço da pesquisa tecnológica ou mesmo com o incremento da Pesquisa e Desenvolvimento (P\&D) local (Consoni, 2004).

Consideramos que as atividades de DP envolvem as fases projetar, construir e testar (Thomke \& Fujimoto, 1999), relacionando, de acordo com Brown e Eisenhardt (1995): a) a utilização de redes de fornecedores; b) a presença de equipes multifuncionais; c) a gerência oferecendo senso de direção à equipe; d) o conceito de integridade do produto, que implica uma visão clara da imagem e desempenho do produto; e) as atividades de pré-desenvolvimento, de forma a resolver conflitos 
antecipadamente, acomodando questões políticas e desigualdades funcionais; e f) o alto grau de foco no sistema, de modo a selecionar escolhas tecnológicas dos componentes, a fim de que se ajustem no produto como um todo.

Trataremos neste trabalho das atividades de Desenvolvimento de Produtos de empresas dentro do contexto de cadeias de suprimentos, campo de estudos relativamente recente. Apenas no início da década de 90, lastreado pelo amplo desenvolvimento da logística, o assunto começa a ser sistematicamente tratado em periódicos científicos nas áreas de Administração e Engenharia de Produção no ocidente, com a difusão do novo padrão de relacionamento entre montadoras e fornecedores da indústria automobilística japonesa (Alves Filho, Cerra, Maia, Sacomano Neto, \& Bonadio, 2004).

Relações montadora-fornecedor podem ser definidas, segundo Kotabe, Martin e Domoto (2003), como conjunto de práticas e rotinas que apóiam trocas econômicas entre duas firmas, e se referem ao fato de duas firmas virem fazendo negócios continuamente em um dado período de tempo.

A Gestão da Cadeia de Suprimentos é conceito desenvolvido com enfoque holístico, que gerencia além das fronteiras da empresa. Reconhece-se que há benefícios significativos a serem alcançados ao tentar dirigir estrategicamente toda uma cadeia em direção à satisfação dos clientes finais (Lumus, Vokurka, \& Alber, 1998).

Neste contexto, consideramos que as montadoras brasileiras adotaram estratégias competitivas diferentes nos últimos quinze anos, tendo estabelecido novas formas de relacionamento com os fornecedores de autopeças, inseridas em novas cadeias industriais e tendo, por conseguinte, que adotar estratégias de Desenvolvimento de Produtos e práticas administrativas de Gestão da Cadeia de Suprimentos que fossem adequadas a esses novos contextos.

Este trabalho tem por objetivo comparar os graus de autonomia tecnológica conquistados por três montadoras de motores instaladas no Brasil, bem como identificar as atividades de Desenvolvimento de Produtos que essas subsidiárias realizam em conjunto com os fornecedores.

A autonomia tecnológica dessas subsidiárias do setor automobilístico consiste na independência que elas possuem em relação às suas respectivas matrizes estrangeiras para desenvolverem atividades locais de projeto.

O debate em torno das relações entre estratégias de diferentes empresas que compõem cadeias de suprimentos e o fato de as atividades tecnológicas no setor automobilístico corresponderem a uma parcela substancial do esforço de inovação realizado na indústria brasileira como um todo justificam a realização deste trabalho. 
As próximas seções tratam da literatura a respeito do Desenvolvimento de Produtos na Indústria Automobilística Brasileira, Gestão da Cadeia de Suprimentos e o Método do trabalho, respectivamente. Em seguida, realizamos a apresentação e análise dos estudos de caso e, finalmente, as considerações finais.

\section{Desenvolvimento de Produtos na Indústria Automobilística BRASILEIRA}

Acreditava-se que as subsidiárias se mantinham totalmente dependentes das suas empresas matrizes quanto ao desenvolvimento de produtos tecnologicamente mais sofisticados e à introdução de processos de produção mais inovadores. Entretanto no Brasil esta concepção se vem tornando equivocada.

A princípio houve uma tentativa de padronização do design, porém adaptações locais foram necessárias no Brasil, dada as preferências dos consumidores locais, as diferentes condições das estradas, as características de materiais locais e especificações e custos em relação a regras locais em segurança e poluição (Humphrey \& Salerno, 2000).

Assim, as capacidades tecnológicas acumuladas nesses países estavam limitadas a esforços localizados de adaptação dos produtos e dos processos de manufatura às condições locais de mercados e insumos, e que se sustentavam a partir da incorporação de tecnologias geradas no exterior (Consoni, 2004).

Segundo Humphrey e Salerno (2000), novos investimentos em mercados emergentes tornaram-se estratégicos não apenas para montadoras, mas também para os fornecedores dos primeiros níveis e subsidiárias de companhias transnacionais. Consequientemente, as indústrias automobilísticas desses países têm sido estruturalmente transformadas, onde atividades de desenvolvimento de produtos têm sido realizadas.

A pesquisa empírica de Dias e Salerno (2003) indica que as razões que levam uma firma transnacional a descentralizar o desenvolvimento de seus produtos globais vão além dos motivos comumente alegados na literatura, tais como a necessidade de estar próximo ao mercado e o acesso à tecnologia local. Para os autores, a decisão sobre centralizar ou não o desenvolvimento de produtos globais relaciona-se a opções estratégicas que visam aumentar a competitividade da empresa. Desse modo, a busca pela redução do tempo de desenvolvimento também é fator que explica a opção pela descentralização, quando os produtos destinados aos mercados das subsidiárias sofrem muitas adaptações com relação aos produzidos pelos centros de projeto e quando o tempo for dimensão competitiva importante para a empresa. 
A acumulação de capacidades e recursos em uma subsidiária depende, dentre outros fatores, de desenvolvimento criativo e de novas combinações de conhecimentos (Gomes, 2003).

As organizações necessitam de conhecimentos adquiridos anteriormente para assimilarem e explorarem um novo conhecimento, de modo que o acúmulo de recursos depende também da 'capacidade de absorção' (absorptive capability) (Cohen \& Levinthal, 1990).

A capacidade de absorção é influenciada pela participação histórica em específicos mercados de produtos, linhas de $\mathrm{P} \& \mathrm{D}$ e outras atividades técnicas, e a habilidade de absorver capacidades de parceiros depende de relações anteriores com outras firmas (Mowery, Oxley, \& Silverman, 1996; Powell, Koput, \& SmithDoerr, 1996). Segundo estes autores, a capacidade de absorção resulta de um processo prolongado de investimentos, em que a acumulação de conhecimentos dentro da firma e seu desenvolvimento seguem trajetórias tecnológicas.

No que se refere à localização das atividades de P\&D das empresas automobilísticas que operam no Mercosul, as principais tendências são muito influenciadas pelas distintas estratégias de globalização adotadas pelas montadoras (Carvalho et al., 2000). Segundo os resultados da pesquisa realizada por estes autores, a GM e a Fiat adotaram enfoque multi-regional de globalização, com maior autonomia concedida a suas divisões regionais ou subsidiária local, e aumentaram suas atividades tecnológicas, especialmente relacionadas com o desenvolvimento de produtos, assim como ampliaram seus staffs de engenheiros nos anos recentes. A Ford adotou uma estratégia transnacional de globalização e diminuiu o tamanho e a qualidade de sua área de P\&D.

A VW, no início de suas operações no Brasil, optou por realizar localmente certas atividades de DP que a princípio eram essencialmente adaptações de produtos, e que ao longo do tempo resultaram em competências técnicas e gerenciais para projetos. Tais atividades diminuíram após a abertura do mercado, porém foram retomadas no início dos anos 2000 (Dias \& Salerno, 2003).

Durante este mesmo período, novas montadoras surgiram no cenário brasileiro (Renault e PSA, Peugeot Citroen, Toyota, Honda e Daimler Chrysler), centralizando em suas matrizes estrangeiras as atividades de engenharia, sobretudo em relação aos estágios do processo de DP (Consoni, 2004).

Desse modo, podemos dizer que algumas montadoras tendem a contribuir mais do que outras para o desenvolvimento tecnológico brasileiro.

As diversas montadoras instaladas no Brasil modernizaram seus produtos e 
processos de fabricação e exerceram papel ativo no processo de atrair fornecedores de seus países de origem.

Essas montadoras ganharam poder tanto em relação aos fornecedores multinacionais como principalmente em relação aos nacionais, pois a presença de capital nacional no setor ficou cada vez mais restrita a pequenas e, no máximo médias empresas, com produtos menos sofisticados e de menor valor agregado, no segundo ou terceiro nível da cadeia de fornecimento. Portanto, nas áreas de maior conteúdo tecnológico, praticamente só permaneceram empresas multinacionais no primeiro nível de fornecimento das montadoras de automóveis (Rachid, 2000).

O processo de reestruturação produtiva nas empresas do setor de autopeças tem ocorrido, em grande medida, em decorrência das inovações introduzidas pelas empresas montadoras, suas principais clientes que exercem grande pressão sobre os fornecedores, sobretudo na fixação dos preços e as especificações técnicas, de forma a garantir controle mais sistêmico do processo produtivo ao longo da cadeia (Previtalli, 2000).

\section{Gestão da Cadeia de Suprimentos - GCS (Supply Chain MANAGEMENT)}

Segundo Cooper, Lambert e Pagh (1997); Tan (2002), a GCS envolve a integração dos processos de negócios através da cadeia de suprimentos, abrangendo a coordenação de atividades e processos não apenas dentro de uma organização isolada, mas entre todas as que compõem a cadeia de suprimentos. A GCS baseia-se na idéia de que empresas devem estar estrategicamente e holisticamente integradas com os seus fornecedores e clientes.

Isto requer que cada estágio leve em consideração o impacto que suas ações exercem sobre outros estágios e, assim, a falta de coordenação ocorre quando cada estágio da cadeia de suprimentos otimiza apenas seu próprio objetivo, sem considerar o impacto na cadeia inteira e também quando há distorção de informações na cadeia.

Desse modo, admite-se que as características das cadeias podem ser transformadas pela prática da GCS, com benefícios para as empresas que compõem a cadeia de suprimentos.

O princípio básico da GCS é "assegurar maior visibilidade dos eventos relacionados à satisfação da demanda, com o objetivo de minimizar os custos das operações produtivas e logísticas entre empresas, constituintes do fluxo de 
materiais, componentes e produtos acabados" (Christopher, 1997; Handfield \& Nichols, 1999; Chopra \& Meindel, 2003 como citado em Assumpção, 2003, p. 346), tornando os processos de negócios mais eficientes e eficazes, reduzindo custos, níveis de estoque, melhorando a qualidade e criando vantagem competitiva e valor para a cadeia de suprimentos (Alves Filho et al., 2001).

O envolvimento conjunto das empresas em $\mathrm{P} \& \mathrm{D}$ é uma prática que se tem expandido no contexto da GCS, assim como o envolvimento de fornecedores no processo de desenvolvimento e fabricação de novos produtos (Tan, 2002). Segundo Ragatz et al. (1997 como citado em Assumpção, 2003), quanto mais cedo no processo de desenvolvimento do produto for estabelecida a integração entre clientes e fornecedores no projeto de novos produtos, mais efetiva será a redução de custos e de tempo de seu desenvolvimento.

A Figura 1, a seguir, sintetiza os principais pressupostos de GCS mencionados na literatura, agrupados em quatro subconjuntos relacionados, respectivamente, (1) ao ambiente competitivo; (2) ao alinhamento estratégico das organizações e à repartição dos ganhos; (3) à estrutura da cadeia; e (4) às relações entre as empresas da cadeia.

Figura 1: Principais Pressupostos da Gestão da Cadeia de Suprimentos

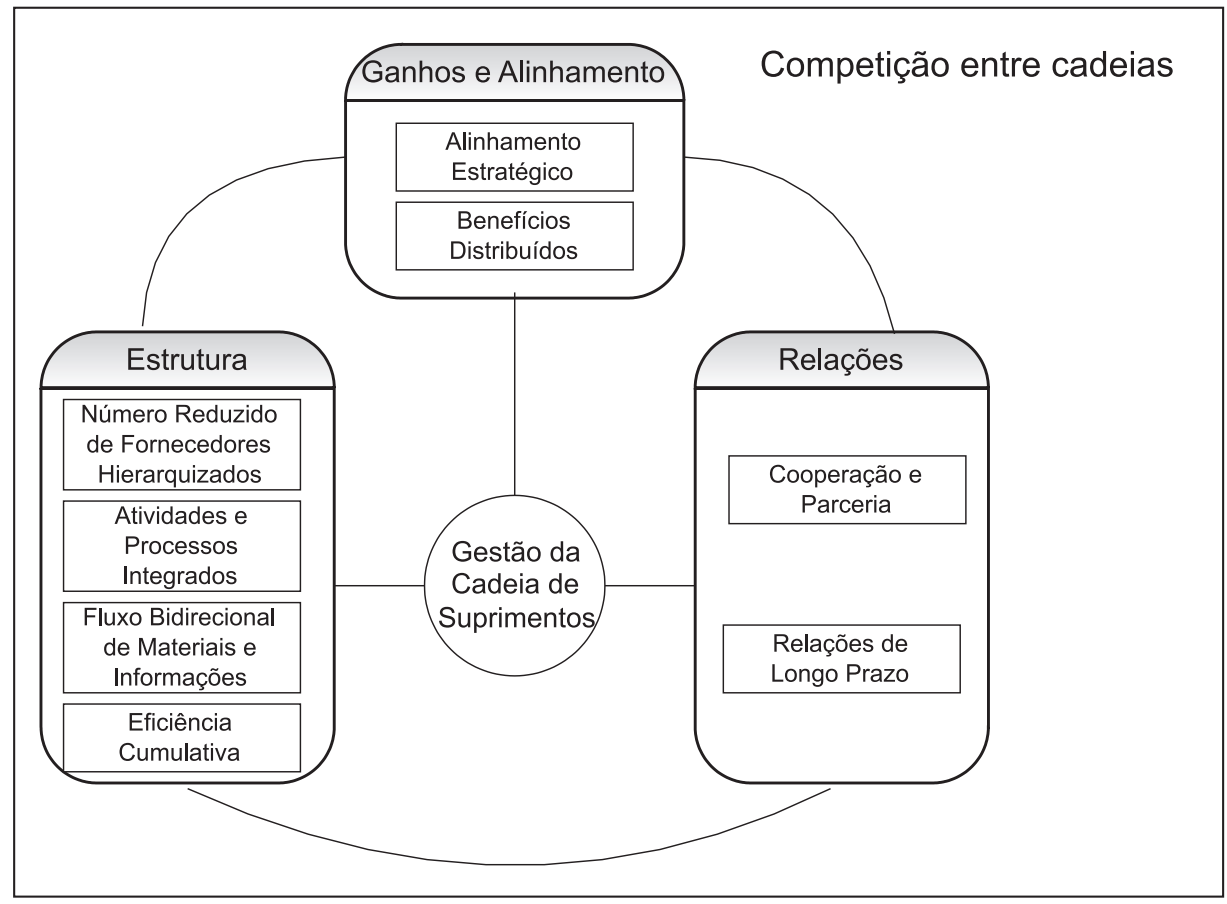

Fonte: Alves Filho et al., 2004. 
O primeiro subconjunto de pressupostos, e o mais importante, embasa todos os outros aqui apresentados. Refere-se à maneira como as companhias e pesquisadores percebem o ambiente competitivo, considerando que a competição ocorre entre cadeias inteiras, e não entre empresas isoladas.

O segundo grupo de pressupostos deriva do primeiro. Se agora a competição ocorre entre cadeias inteiras, as companhias devem ter suas estratégias alinhadas, de forma que ações individuais gerem ganhos para toda a cadeia. A contrapartida do alinhamento estratégico seria uma distribuição de ganhos equânime entre as empresas, de acordo com os esforços e investimentos feitos por cada uma.

O terceiro subconjunto contempla aspectos relativos à estrutura, isto é, o papel que cada companhia e unidade produtiva devem desempenhar dentro das cadeias. Ele inclui a existência de um pequeno número de fornecedores hierarquizados, a integração de processos e atividades através da cadeia, a ocorrência de fluxo bidirecional eficiente de materiais e informação, e os esforços que cada companhia realiza de forma a reduzir sua própria complexidade, reduzindo assim a complexidade da cadeia como um todo.

O quarto grupo se refere às relações entre as companhias dentro da cadeia de suprimentos. Ele lida com o estabelecimento de relações cooperativas e de longo prazo, assim como parcerias entre as empresas.

Para Ballou (2001), o aumento do interesse pelas relações de parceria deve-se ao fato de não existir mais a possibilidade de uma única empresa ter todo o controle do fluxo dos produtos ou serviços, da fonte da matéria-prima ao consumo final.

\section{MÉTOdO}

Este trabalho consiste em pesquisa qualitativa, que se utilizou do estudo de caso como estratégia de análise. Segundo Yin (1989, p. 23), esse método propõe "investigar um fenômeno atual dentro do seu contexto real, quando as fronteiras entre o fenômeno e o contexto não são claramente definidas e no qual são utilizadas várias fontes de evidência".

É também uma pesquisa descritiva (ou exploratória).

Foram conduzidas entrevistas semi-estruturadas em três montadoras de motores 
para automóveis, que duraram cerca de uma hora cada, com a utilização de questionário formulado a partir da revisão da literatura.

As empresas escolhidas pertencem ao grupo das montadoras que se instalaram no Brasil logo no início do desenvolvimento da Indústria Automobilística do país, e que apresentam investimentos em $P \& D$ menos centralizados na matriz estrangeira, quando comparados aos realizados pelas montadoras que aqui se instalaram após os anos 90 .

Outro aspecto considerado na escolha das empresas foi a facilidade de acesso a elas.

A tabela a seguir sintetiza as entrevistas realizadas nas empresas.

Tabela 1: Entrevistas Realizadas nas Três Montadoras de Motores

\begin{tabular}{|c|c|c|c|}
\hline & Montadora A & Montadora B & Montadora C \\
\hline $\begin{array}{l}\text { Entrevistados da área de } \\
\text { Tecnologia de Produtos e } \\
\text { de Processos }\end{array}$ & $\begin{array}{l}* \text { Gerente Executivo de } \\
\text { Engenharia (dez/2004) } \\
* \text { Gerente da Engenharia } \\
\text { de PTO (maio/2004) } \\
* \text { Engenheiro de Novos } \\
\text { Projetos (junho/2004) } \\
* \text { Engenheiro Industrial } \\
\text { (Processos) } \\
\text { (setembro/2004) } \\
\end{array}$ & $\begin{array}{l}* \text { Engenheiro de Projetos } \\
\text { de Motores (maio/2004) }\end{array}$ & $\begin{array}{l}* \text { Engenheiro de Projetos } \\
\text { de Motores/ Componentes } \\
\text { Elétricos (julho/2004) }\end{array}$ \\
\hline $\begin{array}{l}\text { Entrevistados da área de } \\
\text { Gestão de Cadeias de } \\
\text { Suprimentos }\end{array}$ & $\begin{array}{l}* \text { Supervisor de Compras } \\
* \text { Supervisor de Q.A. } \\
\text { Peças (dezembro/2004) } \\
\text { * Gerente de Produção } \\
\text { * Responsável pela } \\
\text { Logística (fevereiro/2005) }\end{array}$ & $\begin{array}{l}* \text { Gerente de Compras } \\
\text { (maio/2004) } \\
\text { * Gerente de Processos de } \\
\text { Montagem de Motores } \\
\text { (fevereiro/2004) }\end{array}$ & $\begin{array}{l}* \text { Gerente de } \\
\text { (maio/2004) } \\
* \text { Gerente de } \\
\text { (julho/2004) } \\
\text { * Redução } \\
\text { Logística (julho/2004) }\end{array}$ \\
\hline
\end{tabular}

\section{Estudos de Caso}

Os estudos de caso foram realizados em três montadoras de motores para automóveis do setor automobilístico brasileiro. De forma a não identificá-las, elas serão aqui chamadas de montadoras $\mathrm{A}, \mathrm{B}$ e C.

A montadora A produz motores para automóveis (motores 1.0 a 1.6), envolvendo grande diversidade de produtos.

Trabalha em 3 turnos de produção, sendo que o terceiro turno produz metade da produção dos demais. Cada turno tem a capacidade de produzir 600 motores, mas produz 550 devido ao mix de produção. Desta forma, a planta possui capacidade de produção aproximada de 1.300 motores por dia. 
A montadora B produz motores para automóveis tanto no segmento de baixa e média cilindrada (1.0 a 1.8), quanto em alta cilindrada (2.0 a 2.4, incluindo também motores 1.8 com 8 e 16 válvulas nesta família de produtos).

Na linha de motores 1.0 a 1.8, a montadora possui capacidade para produzir cerca de 1.650 motores/dia ( 80 horas em 3 turnos de produção). A produção em 2004 foi estimada em 441.000 motores.

Já na linha de motores 2.0 a 2.4, possui capacidade para produzir cerca de 836 motores/dia. A estimativa para 2004 foi produzir 105.000 unidades.

A montadora $\mathrm{C}$ lida com motores de baixa e média cilindradas (motores $1.0 \mathrm{a}$ $1.8)$.

Possui capacidade instalada para a produção de 1.900 motores/dia em três turnos, e 1.700 transmissões, também em três turnos.

A Tabela 2 sintetiza as principais informações relativas ao Desenvolvimento de Produtos nas três montadoras.

\section{Tabela 2: Características da Estrutura de Desenvolvimento de Produtos das Montadoras}

\begin{tabular}{|c|c|c|c|}
\hline & $\begin{array}{c}\text { Montadora de Motores } \\
\text { A } \\
\end{array}$ & $\begin{array}{c}\text { Montadora de Motores } \\
\text { B } \\
\end{array}$ & $\begin{array}{c}\text { Montadora de Motores } \\
\text { C }\end{array}$ \\
\hline Principais Produtos & $\begin{array}{c}\text { Motores para } \\
\text { automóveis (motores } 1.0 \\
\text { a } 1.6 \text { envolvendo uma } \\
\text { grande diversidade de } \\
\text { produtos). }\end{array}$ & $\begin{array}{c}\text { Motores para } \\
\text { automóveis (motores } 1.0 \\
\text { a } 1.8 \text { e também motores } \\
2.0 \text { a } 2.4) .\end{array}$ & $\begin{array}{l}\text { Motores para automóveis } \\
\text { (motores } 1.0 \text { a } 1.8 \\
\text { envolvendo uma grande } \\
\text { diversidade de produtos). }\end{array}$ \\
\hline $\begin{array}{c}\text { Projetos recentes nos } \\
\text { quais a empresa está } \\
\text { trabalhando: }\end{array}$ & $\begin{array}{l}\text { - } \text { adequação de novas } \\
\text { emissões de } \\
\text { poluentes de } \\
\text { motores; } \\
\text { - motor a gás; } \\
\text { - motor para um carro } \\
\text { que será exportado; } \\
\text { adequação de } \\
\text { transmissões a } \\
\text { novos tipos de } \\
\text { motores. }\end{array}$ & $\begin{array}{c}\text { A empresa não revelou } \\
\text { quais são os projetos } \\
\text { atuais. }\end{array}$ & $\begin{array}{l}\text { A empresa não revelou } \\
\text { quais são os projetos } \\
\text { atuais, mas informou que } \\
\text { há grande número de } \\
\text { projetos. }\end{array}$ \\
\hline
\end{tabular}




\section{(continuação) \\ Tabela 2: Características da Estrutura de Desenvolvimento de Produtos das Montadoras}

\begin{tabular}{|c|c|c|c|}
\hline & $\begin{array}{c}\text { Montadora de Motores } \\
\text { A }\end{array}$ & $\begin{array}{c}\text { Montadora de Motores } \\
\text { B }\end{array}$ & $\begin{array}{c}\text { Montadora de Motores } \\
\text { C }\end{array}$ \\
\hline $\begin{array}{c}\text { Setor responsável } \\
\text { pelas atividades de } \\
\text { Desenvolvimento de } \\
\text { Produtos } \\
\text { (valores aproximados) }\end{array}$ & $\begin{array}{l}\text { Existe um total de } 680 \\
\text { pessoas atuando na } \\
\text { Engenharia de Produto } \\
\text { no Brasil, e cerca de } 550 \\
\text { deles são engenheiros. } \\
\text { No segmento de } \\
\text { motores: } 180 \text { pessoas } \\
\text { Curso superior: } 180 \\
\text { Pós-Graduação: } 108 \\
\text { Técnicos: grande parte } \\
\text { fez curso técnico antes } \\
\text { de cursar engenharia. } \\
\text { - Contrata projetistas } \\
\text { temporários. } \\
\text { - Bastante interação } \\
\text { com a matriz } \\
\text { (exterior). } \\
\text { - Alguns engenheiros } \\
\text { estão fazendo } \\
\text { estágio na matriz } \\
\text { (exterior). } \\
\Rightarrow \text { O n }{ }^{\circ} \text { total diminuiu } \\
\text { nos últimos anos, } \\
\text { quando ocorreu uma } \\
\text { redução do n }{ }^{\circ} \text { total de } \\
\text { funcionários da empresa. }\end{array}$ & $\begin{array}{l}\text { No segmento de } \\
\text { motores: } 190 \text { pessoas } \\
\text { Curso superior: } 100 \\
\text { Pós-Graduação: } 20 \\
\text { Técnicos: } 13 \\
\text { Outros: } 62 \\
\text { - Contrata projetistas } \\
\text { temporários. } \\
\text { - Bastante interação } \\
\text { com a matriz } \\
\text { (exterior). } \\
\Rightarrow \text { O n }{ }^{\circ} \text { total de pessoas } \\
\text { do setor aumentou em } 50 \\
\text { nos últimos anos. }\end{array}$ & $\begin{array}{l}\text { - Contrata projetistas } \\
\text { temporários. } \\
\text { - Bastante interação } \\
\text { com a matriz } \\
\text { (exterior). } \\
\text { - Alguns engenheiros } \\
\text { estão fazendo estágio } \\
\text { na matriz (exterior). } \\
\\
\Rightarrow \text { O nº total de pessoas } \\
\text { do setor aumentou nos } \\
\text { últimos anos. }\end{array}$ \\
\hline $\begin{array}{c}\text { Autonomia } \\
\text { Tecnológica em } \\
\text { relação à matriz }\end{array}$ & $\begin{array}{l}\text { - Possui autonomia } \\
\text { para desenvolver } \\
\text { motores a partir de } \\
\text { motores existentes. } \\
\text { Destacam-se os } \\
\text { desenvolvimentos } \\
\text { locais: } \\
\text { - motores a álcool; } \\
\text { - motores } 1.0 \\
\text { inexplorados pela } \\
\text { concorrência; } \\
\text { - motores } 1.0 \text { com } \\
\text { 16V para exportação; } \\
\text { - motor } 1.4 \text { para um } \\
\text { carro utilizado na } \\
\text { Europa; } \\
\text { - motores bi- } \\
\text { combustíveis. } \\
\Rightarrow \text { Autonomia para } \\
\text { inovações em processos. }\end{array}$ & $\begin{array}{l}\text { - Possui autonomia } \\
\text { para desenvolver } \\
\text { motores a partir de } \\
\text { motores existentes. } \\
\text { Destacam-se os } \\
\text { desenvolvimentos } \\
\text { locais: } \\
\text { - transmissão; } \\
\text { - motores a álcool; } \\
\text { - materiais visando } \\
\text { resistência à } \\
\text { corrosão; } \\
\text { - motores 1.0; } \\
\text { - motores bi- } \\
\text { combustíveis. }\end{array}$ & $\begin{array}{l}\text { - Possui autonomia para } \\
\text { desenvolver motores a } \\
\text { partir de motores } \\
\text { existentes. } \\
\text { Destacam-se os } \\
\text { desenvolvimentos } \\
\text { locais: } \\
\text { - precursora do motor a } \\
\text { álcool; } \\
\text { - materiais visando } \\
\text { resistência à corrosão; } \\
\text { - as linhas de motores } \\
\text { fabricadas no Brasil } \\
\text { foram desenvolvidas } \\
\text { na matriz com a } \\
\text { participação de } \\
\text { engenheiros } \\
\text { brasileiros. } \\
\text { - motores bi- } \\
\text { combustíveis. } \\
\Rightarrow \text { Autonomia para } \\
\text { inovações em processos. }\end{array}$ \\
\hline
\end{tabular}




\section{(conclusão)}

\section{Tabela 2: Características da Estrutura de Desenvolvimento de Produtos das Montadoras}

\begin{tabular}{|c|c|c|c|}
\hline & $\begin{array}{c}\text { Montadora de Motores } \\
\text { A }\end{array}$ & $\begin{array}{c}\text { Montadora de Motores } \\
\text { B } \\
\end{array}$ & $\begin{array}{c}\text { Montadora de Motores } \\
\text { C } \\
\end{array}$ \\
\hline $\begin{array}{c}\text { Estratégias de } \\
\text { Desenvolvimento de } \\
\text { Produtos (DP) }\end{array}$ & $\begin{array}{l}\text { DP para mercados } \\
\text { emergentes: motor de } \\
\text { baixa cilindrada e maior } \\
\text { potência; motor com } \\
\text { sistema de combustível } \\
\text { flexível. }\end{array}$ & $\begin{array}{l}\text { DP para mercados } \\
\text { emergentes: motor de } \\
\text { baixa cilindrada e maior } \\
\text { potência; motor com } \\
\text { sistema de combustível } \\
\text { flexível. }\end{array}$ & $\begin{array}{c}\text { DP para mercados } \\
\text { emergentes: motor com } \\
\text { sistema de combustível } \\
\text { flexível. } \\
\text { A meta é ter autonomia } \\
\text { em DP para mercados } \\
\text { emergentes. }\end{array}$ \\
\hline $\begin{array}{l}\text { Relações com centros } \\
\text { de pesquisa ou } \\
\text { universidades para } \\
\text { desenvolvimento de } \\
\text { projetos ou aquisição } \\
\text { de tecnologia }\end{array}$ & $\begin{array}{c}\text { Apenas realiza testes em } \\
\text { dinamômetros em } \\
\text { parceria com uma } \\
\text { universidade. }\end{array}$ & $\begin{array}{c}\text { Apenas realiza testes em } \\
\text { dinamômetros em } \\
\text { parceria com uma } \\
\text { universidade. }\end{array}$ & $\begin{array}{l}\text { Realiza testes em } \\
\text { dinamômetros em } \\
\text { parceria com uma } \\
\text { universidade e possui } \\
\text { relações com uma } \\
\text { universidade federal. }\end{array}$ \\
\hline $\begin{array}{l}\text { Treinamento de } \\
\text { funcionários }\end{array}$ & $\begin{array}{l}\text { No início da produção da } \\
\text { fábrica foram feitos } \\
\text { investimentos intensivos } \\
\text { em treinamento de } \\
\text { funcionários. } \\
\text { A empresa continua } \\
\text { investindo em } \\
\text { treinamento de } \\
\text { funcionários, } \\
\text { especialmente para a } \\
\text { qualidade. }\end{array}$ & $\begin{array}{l}\text { Embora os investimentos } \\
\text { em treinamentos estejam } \\
\text { diminuindo, existem } \\
\text { treinamentos voltados } \\
\text { para melhorias de } \\
\text { produtos e processos, } \\
\text { conforme as } \\
\text { necessidades da } \\
\text { empresa. }\end{array}$ & $\begin{array}{c}\text { Atualmente os } \\
\text { treinamentos estão mais } \\
\text { focados, ou seja, mais } \\
\text { direcionados às } \\
\text { necessidades. A carga } \\
\text { horária aumentou e } \\
\text { existem mais funcionários } \\
\text { com aptidão para fazer } \\
\text { treinamentos. }\end{array}$ \\
\hline $\begin{array}{l}\text { Exploração de } \\
\text { tecnologias }\end{array}$ & $\begin{array}{c}\text { Não realiza a exploração } \\
\text { comercial de tecnologias } \\
\text { dominadas (não compra } \\
\text { ou licencia tecnologias } \\
\text { de produto e processos } \\
\text { desenvolvidas por outras } \\
\text { empresas para incorporar } \\
\text { em seus próprios } \\
\text { produtos e processos). }\end{array}$ & $\begin{array}{l}\text { Não realiza a exploração } \\
\text { comercial de tecnologias } \\
\text { dominadas (não compra } \\
\text { ou licencia tecnologias } \\
\text { de produto e processos } \\
\text { desenvolvidas por outras } \\
\text { empresas para incorporar } \\
\text { em seus próprios } \\
\text { produtos e processos). }\end{array}$ & $\begin{array}{c}\text { Não realiza a exploração } \\
\text { comercial de tecnologias } \\
\text { dominadas (não compra } \\
\text { ou licencia tecnologias de } \\
\text { produto e processos } \\
\text { desenvolvidas por outras } \\
\text { empresas para incorporar } \\
\text { em seus próprios produtos } \\
\text { e processos). }\end{array}$ \\
\hline
\end{tabular}

A Tabela 3, a seguir, sintetiza as principais informações relativas à Gestão da Cadeia de Suprimentos das três montadoras.

\section{Tabela 3: Características Relevantes da Gestão da Cadeia de Suprimentos das Montadoras}

\begin{tabular}{|c|c|c|c|}
\hline & $\begin{array}{c}\text { Montadora de Motores } \\
\text { A }\end{array}$ & $\begin{array}{c}\text { Montadora de Motores } \\
\text { B }\end{array}$ & $\begin{array}{c}\text { Montadora de Motores } \\
\text { C }\end{array}$ \\
\hline Principais clientes & $\begin{array}{c}\text { A montadora de } \\
\text { automóveis. }\end{array}$ & $\begin{array}{c}\text { As unidades montadoras } \\
\text { de automóveis. }\end{array}$ & $\begin{array}{c}\text { As unidades montadoras } \\
\text { de automóveis. }\end{array}$ \\
\hline $\begin{array}{c}\text { Número de } \\
\text { fornecedores diretos } \\
\text { (valores aproximados) }\end{array}$ & $\begin{array}{c}\text { O número aumentou } \\
\text { nos últimos anos. }\end{array}$ & $\begin{array}{c}\text { O número diminuiu } \\
\text { nos últimos anos. }\end{array}$ & $\begin{array}{c}\text { O número diminuiu } \\
\text { nos últimos anos. }\end{array}$ \\
\hline $\begin{array}{c}\text { Critérios para a } \\
\text { seleção } \\
\text { fornecedores }\end{array}$ & $\begin{array}{c}\text { Preço, capacidade } \\
\text { tecnológica e qualidade. }\end{array}$ & $\begin{array}{c}\text { Qualidade, preço, } \\
\text { capacidade } \\
\text { tecnológica e relação } \\
\text { comercial. }\end{array}$ & $\begin{array}{c}\text { Qualidade, preço, } \\
\text { capacidade } \\
\text { tecnológica e relação } \\
\text { comercial. }\end{array}$ \\
\hline
\end{tabular}


(conclusão)

Tabela 3: Características Relevantes da Gestão da Cadeia de
Suprimentos das Montadoras

\begin{tabular}{|c|c|c|c|}
\hline & $\begin{array}{c}\text { Montadora de Motores } \\
\text { A }\end{array}$ & $\begin{array}{c}\text { Montadora de Motores } \\
\text { B }\end{array}$ & $\begin{array}{c}\text { Montadora de Motores } \\
\text { C }\end{array}$ \\
\hline $\begin{array}{l}\text { Porte dos principais } \\
\text { fornecedores } \\
\text { (valores } \\
\text { aproximados) }\end{array}$ & $\begin{array}{c}70 \% \text { do total de } \\
\text { fornecedores são } \\
\text { empresas de grande } \\
\text { porte. }\end{array}$ & $\begin{array}{c}80 \% \text { do total de } \\
\text { fornecedores são } \\
\text { empresas de grande } \\
\text { porte. }\end{array}$ & $\begin{array}{c}80 \% \text { do total de } \\
\text { fornecedores são } \\
\text { empresas de grande } \\
\text { porte. }\end{array}$ \\
\hline $\begin{array}{l}\text { Número de } \\
\text { fornecedores por } \\
\text { componente } \\
\text { terceirizado }\end{array}$ & $\begin{array}{c}\text { Dependendo do } \\
\text { componente em questão, } \\
\text { pode haver um, dois ou } \\
\text { três fornecedores. }\end{array}$ & $\begin{array}{l}\text { Um fornecedor para cada } \\
\text { item comprado. }\end{array}$ & $\begin{array}{l}\text { Um fornecedor para cada } \\
\text { item comprado. }\end{array}$ \\
\hline $\begin{array}{l}\text { Fornecedores } \\
\text { exclusivos (por } \\
\text { empresa ) }\end{array}$ & $\begin{array}{l}\text { Existem fornecedores } \\
\text { quase exclusivos. }\end{array}$ & Não há. & Não há. \\
\hline $\begin{array}{l}\text { Componentes } \\
\text { terceirizados }\end{array}$ & $\begin{array}{c}\text { Desde o início da } \\
\text { produção, possui alto } \\
\text { nível de outsourcing, } \\
\text { quando comparada às } \\
\text { demais montadoras. } \\
\text { Terceiriza componentes } \\
\text { que não são considerados } \\
\text { tecnologicamente } \\
\text { estratégicos para a } \\
\text { empresa. } \\
\text { Faz a usinagem } \\
\text { internamente e terceiriza } \\
\text { a fundição. }\end{array}$ & $\begin{array}{l}\text { Realizou outsourcing de } \\
\text { grande parte de seus } \\
\text { componentes } \\
\text { recentemente. } \\
\text { Terceiriza componentes } \\
\text { que não são considerados } \\
\text { tecnologicamente } \\
\text { estratégicos para a } \\
\text { empresa. } \\
\text { Terceirizou a usinagem e } \\
\text { tem a intenção de } \\
\text { terceirizar a fundição. }\end{array}$ & $\begin{array}{c}\text { Terceiriza componentes } \\
\text { que não são considerados } \\
\text { tecnologicamente } \\
\text { estratégicos para a } \\
\text { empresa. } \\
\text { Faz internamente a } \\
\text { usinagem do bloco } \\
\text { motor, virabrequim e } \\
\text { cabeçote. }\end{array}$ \\
\hline $\begin{array}{l}\text { Avaliação de } \\
\text { Fornecedores }\end{array}$ & $\begin{array}{l}\text { Avalia os fornecedores } \\
\text { com os mesmos } \\
\text { critérios } \\
\text { da seleção: preço, } \\
\text { capacitação } \\
\text { tecnológica } \\
\text { e qualidade. }\end{array}$ & $\begin{array}{l}\text { Avalia os fornecedores } \\
\text { com os mesmos } \\
\text { critérios da seleção: } \\
\text { qualidade, preço, } \\
\text { capacitação } \\
\text { tecnológica e relação } \\
\text { comercial. } \\
\end{array}$ & $\begin{array}{l}\text { Avalia os fornecedores } \\
\text { com os mesmos } \\
\text { critérios da seleção: } \\
\text { qualidade, preço, } \\
\text { capacitação } \\
\text { tecnológica e relação } \\
\text { comercial. } \\
\end{array}$ \\
\hline $\begin{array}{l}\text { Contratos com } \\
\text { fornecedores }\end{array}$ & $\begin{array}{l}\text { Contratos } \\
\text { Formais. }\end{array}$ & $\begin{array}{l}\text { Contratos formais com } \\
\text { vigência de um ano } \\
\text { (renováveis). }\end{array}$ & $\begin{array}{l}\text { Contratos formais com } \\
\text { vigência de um ano } \\
\text { (renováveis). }\end{array}$ \\
\hline $\begin{array}{c}\text { Desenvolvimento em } \\
\text { conjunto de produtos } \\
\text { (co-design) }\end{array}$ & $\begin{array}{l}\text { Realiza para alguns } \\
\text { componentes: } \\
\text { - Sistema Blowby } \\
\text { (desenvolvido com um } \\
\text { fornecedor); } \\
\text { - motor a gás } \\
\text { (desenvolvido com } \\
\text { uma empresa } \\
\text { especializada); } \\
\text { - motor bi- } \\
\text { combustível (com } \\
\text { fornecedores). }\end{array}$ & $\begin{array}{l}\text { Realiza para alguns } \\
\text { componentes: } \\
\text { - transmissão } \\
\text { (desenvolvida em } \\
\text { conjunto com um } \\
\text { fornecedor); } \\
\text { - motor bi- } \\
\text { combustível } \\
\text { (desenvolvido com } \\
\text { fornecedores). }\end{array}$ & $\begin{array}{l}\text { Realiza para alguns } \\
\text { componentes: } \\
\text { - sistemas de injeção } \\
\text { (desenvolvidos com } \\
\text { fornecedores); } \\
\text { - motor bi- } \\
\text { combustível } \\
\text { (desenvolvido com } \\
\text { fornecedores). }\end{array}$ \\
\hline $\begin{array}{l}\text { Relações com outros } \\
\text { elos da cadeia de } \\
\text { suprimentos }\end{array}$ & $\begin{array}{l}\text { A montadora se relaciona } \\
\text { apenas com clientes e } \\
\text { fornecedores diretos. }\end{array}$ & $\begin{array}{l}\text { A montadora se relaciona } \\
\text { apenas com clientes e } \\
\text { fornecedores diretos. }\end{array}$ & $\begin{array}{l}\text { A montadora se relaciona } \\
\text { apenas com clientes e } \\
\text { fornecedores diretos. }\end{array}$ \\
\hline
\end{tabular}




\section{Análise dos Estudos de Caso}

As três empresas estudadas apresentam setores de atividades de Desenvolvimento de Produtos estruturados, integrados com a matriz no exterior e voltados para o aumento da diversidade de produtos.

Apesar de tais semelhanças, enquanto a empresa A reduziu o número total de pessoas envolvidas com desenvolvimento nos últimos anos, quando houve redução de $20 \%$ do total de seus funcionários, na empresa B essa estrutura aumentou em aproximadamente $35 \%$, devido ao aumento do número de projetos em andamento e da autonomia da empresa em relação à matriz no exterior; na empresa $\mathrm{C}$ a estrutura também aumentou com o aumento do número de projetos.

O número de pessoas envolvidas com desenvolvimento tecnológico nas montadoras de motores estudadas tornou-se, após as mudanças ocorridas, muito próximo.

De modo geral, as três empresas possuem autonomia local para desenvolver novos produtos a partir de outros já existentes (possivelmente desenvolvidos em algum momento pela matriz no exterior), além de desenvolverem inovações de processos. Consideram muito importante que haja troca de informações entre os departamentos e entre os funcionários, além da troca de informações com clientes e fornecedores.

Quando as montadoras de motores desenvolvem um novo produto, os fornecedores imediatos (diretos) recebem as especificações necessárias para desenvolver componentes que se adaptem ao novo motor. Do mesmo modo, os fornecedores imediatos passam para alguns de seus fornecedores (os fornecedores de segundo nível das montadoras) especificações para a produção de componentes voltados aos seus novos produtos.

Assim, embora a tecnologia do componente esteja sob domínio do fornecedor, o trabalho de sua 'aplicação' é coordenado pela Engenharia da montadora, a qual também define as normas de aprovação de cada componente. Exemplos de componentes nesse caso são os componentes eletrônicos, as embreagens, dentre outros.

As relações observadas nesse conjunto de empresas caracterizam-se por relações de fornecimento em que cada empresa domina a tecnologia necessária para a produção de seus componentes. Entretanto existem casos em que, tendo o fornecedor capacidade tecnológica limitada, as montadoras lhe transferem o design do produto, restando ao fornecedor adaptar tal projeto ao seu processo de produção. Nesse conjunto de fornecedores, as atividades de Desenvolvimento de Produtos restringem-se a inovações em processos de produção. Exemplos de 
componentes neste caso são: carter, agregados de motor (como, por exemplo, tampa do motor), coletor de escape etc.

Outra possibilidade é a de desenvolvimento de produtos em conjunto (co-design). Entendemos como desenvolvimento em conjunto, ou co-design, as relações em que firmas cooperam com base em suas capacidades tecnológicas.

Os estudos de caso realizados demonstram que as três montadoras de motores realizam co-design para componentes diferenciados, exceto o motor bicombustível, que as três o fazem com fornecedores comuns, conforme demonstra a Tabela 2.

A Montadora A difere das outras duas em aspectos da Gestão da Cadeia de Suprimentos. Possuía inicialmente número maior de fornecedores, aumentou o número deles e possui diferente política de fornecimento (dois ou três fornecedores por item terceirizado). Essa política de duplo (ou múltiplo) fornecimento faz com que haja competição entre os fornecedores, aumentando o poder de negociação da montadora.

Além disso, a Montadora A possui número maior de fornecedores de pequeno porte, com capacidades tecnológicas limitadas, quando comparada às outras duas montadoras. No início da produção da fábrica de motores, a empresa A desenvolveu um conjunto de empresas pequenas, capacitando-as para o fornecimento de componentes conforme suas especificações e normas. Para esses componentes em tela, a montadora adotou a política de um fornecedor por item, porque, caso contrário, teria de investir em mais empresas.

Os fornecedores em geral são dependentes das estratégias das montadoras, aceitando exigências quanto a especificações técnicas e qualidade dos produtos fornecidos, além de seus preços e prazos de entrega. Essa dependência é ainda maior no caso dos fornecedores que foram, em algum momento, desenvolvidos pela montadora (Alves Filho et al., 2001).

Os contatos das montadoras restringem-se aos fornecedores imediatos, de primeiro nível, o que significa que a cadeia não é estrategicamente e holisticamente integrada com a preocupação de atender ao cliente final da melhor maneira possível, conforme sugere a literatura da GCS.

\section{Considerações Finais}

A política tributária instituída na década de 90 , que isentou os veículos com motorização de até 1000 cilindradas das alíquotas do IPI, resultou em diminuição significativa dos preços de mercado desses modelos. Essa medida governamental 
direcionada ao setor automotivo brasileiro teve impactos significativos para as estratégias de atuação local das montadoras, sobretudo em relação às atividades de DP, com a atração de investimentos para o segmento de motores para automóveis.

O motor constitui um sistema considerado estratégico para a competitividade das montadoras de automóveis, sendo composto por grande número de componentes (especialmente no segmento metal-mecânico), de modo que a estratégia de DP dessas montadoras deva estar alinhada à estratégia de suprimentos.

Nas cadeias de suprimentos do segmento de motores, diferentemente do que ocorre entre as montadoras de automóveis, não foram implantados arranjos, como o consórcio modular ou condomínio industrial. As iniciativas quanto ao fornecimento de subconjuntos de maior valor agregado ainda são incipientes e as montadoras de motores têm implementado modelos distintos quanto ao número de fornecedores por componente ou peça adquirida.

Estudos empíricos realizados entre as mondadoras de automóveis instaladas no Brasil revelam que essas empresas possuem diferentes graus de conhecimento acumulado, que se relacionam com distintas estratégias de produtos e localização de P\&D (Consoni, 2004). Consoni analisa o comportamento dessas empresas, organizando-as em dois grupos: as veteranas (com investimentos em P\&D menos centralizados no exterior) e as entrantes (que se instalaram no Brasil a partir dos anos 90, apresentando extrema centralização das atividades de engenharia no exterior, sobretudo em relação aos estágios de DP).

Dentre as montadoras veteranas, onde as empresas estudadas se enquadram, tem-se que as estratégias de localização de atividades de DP variaram no decorrer do tempo. É importante ressaltar que o estudo aqui realizado não é longitudinal, tratando das características recentes das empresas e, assim, as mudanças ocorridas ao longo do tempo não puderam ser observadas em profundidade.

Ao comparar a autonomia concedida à estrutura de Desenvolvimento de Produtos das montadoras de motores estudadas, constatou-se que as três apresentam autonomia crescente em relação às suas respectivas matrizes no exterior para desenvolverem produtos a partir de outros já existentes. As três possuem autonomia para desenvolverem inovações incrementais em processos de produção.

Tais resultados estão de acordo com a pesquisa realizada junto às montadoras de automóveis por Consoni, na medida em que estudamos três das montadoras veteranas, especificamente aquelas que descentralizaram as atividades de DP.

Essas empresas realizaram desenvolvimentos locais importantes, especialmente em motores de baixas cilindradas e de combustíveis flexíveis. Nesse contexto, as montadoras de motores envolveram de algum modo seus fornecedores de 
componentes para motores. Em alguns casos, as montadoras especificam aos fornecedores como devem ser os produtos, e estes os desenvolvem e produzem; em outros casos, as montadoras cedem o design do produto e os fornecedores se responsabilizam apenas pela produção; e ainda há casos em que as montadoras desenvolvem o produto em conjunto com os fornecedores (co-design).

Assim, as estratégias de DP dessas montadoras são em geral muito semelhantes. As diferenças ocorrem em função das estruturas de suas cadeias de fornecedores e de suas políticas de suprimentos, já que a montadora com maior número de fornecedores de menor porte e de capacidade tecnológica limitada deve despender esforço maior para desenvolvê-los e garantir desempenho adequado deles. As montadoras que possuem proporção maior de fornecedores de grande porte e mais capacitados tecnologicamente, por sua vez, devem despender esforços relativamente maiores nas negociações (das transações) com fornecedores, mas seu esforço para desenvolvê-los seria muito menor.

Embora a base de observação empírica possa ser considerada limitada para fazer recomendações sobre GCS, é importante enfatizar que os estudos de caso realizados nas montadoras de automóveis incluíram questões que envolviam tanto os clientes quanto os fornecedores, de forma a cobrir as cadeias de suprimentos.

É necessário considerar também que os fornecedores das companhias estudadas não são exclusivos, participando de várias cadeias do setor automotivo. Assim, os fornecedores principais servem, na maioria dos casos, a montadoras diferentes e necessitam adotar estratégias compatíveis com seus clientes.

Como foi possível observar nos estudos realizados nas empresas, o desenvolvimento de fornecedores não parece ser preocupação principal das montadoras; talvez não seja necessário na maioria dos casos. Mas este tipo de apoio parece ocorrer de maneira intensa em alguns casos, quando o desenvolvimento de um fornecedor (por alguma razão) se torna necessário para a montadora.

Flexibilidade, aspecto muito enfatizado pelos entrevistados, tem impacto na estrutura das cadeias de suprimentos e nos relacionamentos entre as empresas que as compõem. Assim, uma estratégia que parece ser adotada pelas três companhias estudadas é repassar a necessidade de flexibilidade para os mesmos. Desta forma, a montadora atribui a seus fornecedores imediatos a responsabilidade por aumentar flexibilidade e repassar esta demanda ao longo das camadas inferiores da cadeia.

Isso pode corroborar a proposição de Alves Filho et al. (2001), que sugere que nem todos os elos da cadeia devem ser necessariamente coordenados e integrados. 
Assim, determinar quais partes da cadeia merecem mais atenção depende de uma série de fatores que devem ser analisados de acordo com as capacidades da empresa e suas prioridades no momento.

Essas empresas utilizam como critérios para selecionar e avaliar seus fornecedores a sua capacidade tecnológica, assim como o preço e qualidade dos componentes.

As montadoras $\mathrm{B}$ e $\mathrm{C}$ realizam contratos com vigência máxima de um ano, porém as relações de longo prazo parecem ocorrer na prática. No primeiro caso, pode-se verificar que a empresa continua a se relacionar basicamente com os mesmos fornecedores de algum tempo atrás. No segundo caso, os contratos acabam quase sempre sendo renovados, desde que não ocorram impedimentos para isso.

As montadoras exercem alguma influência sobre as cadeias no que se refere às atividades de DP de seus fornecedores, assim como no preço e qualidade dos componentes a elas fornecidos.

Trabalhos futuros poderiam ser realizados, em que uma comparação entre todas as montadoras de motores instaladas no Brasil fosse realizada e maiores variações poderiam surgir.

\section{Artigo recebido em 03.02.2005. Aprovado em 16.09.2005.}

\section{ReferênCIAS Bibliográficas}

Alves Filho, A. G.,

Rachid, A.,

Nogueira, E.,

Donadone, J. C.,

Martins, M. F.,

Truzzi, O. M. S.,

Bento, P. E. G.,

Martins, R. A., \&

Vanalle, R. M. (2001).

O consórcio modular e seus impactos

na cadeia de suprimentos da fábrica de motores VW-São Carlos (Relatório Final, Projeto Temático, Processo FAPESP 97/13071-9). São Carlos, SP, Universidade Federal de São Carlos.
Alves Filho, A. G.,

Cerra, A. L.,

Maia, J. L.,

Sacomano Neto, M., \&

Bonadio, P. V. G. (2004).

Pressupostos do gerenciamento da cadeia de suprimentos: evidências de estudos sobre a indústria automobilística. Gestão \& Produção, 11(3), 275-288.

Assumpção, M. R. P. (2003).

Reflexão para gestão tecnológica em cadeias de suprimentos. Gestão \& Produção, 10(3), 345-362. 
Ballou, R. H. (1999).

Business logistics managemen: planning, organizing and controlling the supply chain (4th ed.). Upper Caddle River: Prentice Hall.

Ballou, R. H. (2001).

Gerenciamento da cadeia de suprimentos: planejamento, organização e logística empresarial. Porto Alegre: Bookman.

Brown, S. L., \&

Eisenhardt, K. M. (1995).

Product development: past research, present findings, and future directions. Academy of Management Review, 20(2), 344-378.

Carvalho, R. Q.,

Queiroz, S. R. R.,

Humphrey, J.,

Consoni, F. L.,

Costa, I., \&

Fonseca, R. R. (2000).

Globalização e reestruturação da cadeia produtiva na indústria automotiva: qual é o papel do Mercosul? (Relatório Final, Convênio IPEA - DPCT/IG/UNICAMP FUNCAMP). Campinas, SP, Universidade de Campinas.

Christopher, M. (1997).

Gerenciamento da cadeia de suprimentos. São Paulo: Pioneira.

Cohen, W. M., \&

Levinthal, D. A. (1990).

Absorptive capacity: a new perspective on learning and innovation (Technology, Organizations and Innovation). Administrative Science Quarterly, 35(1), 128-152.
Cooper, M. C.,

Lambert, D. M., \&

Pagh, J. D. (1997).

Supply chain management: more than a new name for logistics. The International Journal of Logistics Management, 8(1), 1-13.

Consoni, F. L. (2004, abril).

Desenvolvimento de produtos nas montadoras de automóveis no Brasil. Revista Eletrônica de Jornalismo Cientifico Com Ciência, 53, Transportes. Recuperado em 10 novembro, 2004, de http:// www.comciencia.br/200404/ reportagens/13.shtml

Dias, A. V. C., \&

Salerno, M. S. (2003).

Construindo competitividade por meio da organização do desenvolvimento de produtos globais: proposições a partir de estudos de caso no setor automotivo brasileiro. Anais do Encontro Nacional de Engenharia e Produção, Ouro Preto, MG, Brasil, 23.

Gomes, R. (2003).

O papel das subsidiárias e a internacionalização das atividades tecnológicas pelas empresas transnacionais (ETNs). Revista Gestão \& Produção, 10(3), 267-282.

Handfield, R., \&

Nichols, E. (1999).

Introduction to supply chain management. Englewood Cliffs, New Jersey: Prentice Hall. 
Humphrey, J., \&

Salerno, M. S. (2000).

Globalization and assembler-supplier relations: Brazil and India. In J. Humphrey, Y. Lecler, \& M. S. Salerno (Eds.). Global strategies and local realitie: the auto industry in emerging markets. (in association with GERPISA- Resseau International) Basingstoke: Macmillan Press Ltd.

Kotabe, M.,

Martin, X., \&

Domoto, H. (2003).

Gaining from vertical partnerships: knowledge transfer, relationship duration, and supplier performance improvement in the U.S. and Japanese automotive industries. Strategic Management Journal, 24(4), 293-316.

Lumus, R. R.,

Vokurka, R. J., \&

Alber, K. L. (1998).

Strategic supply chain planning. Production and Inventory Management Journal, 39(3), 49-58.

Mowery, D. C.,

Oxley, J. E., \&

Silverman, B. S. (1996).

Strategic alliances and interfirm knowledge transfer. Strategic Management Journal, 17(Winter special issue), 77-91.

Posthuma, A. C. (1997).

Autopeças na encruzilhada: modernização desarticulada e desnacionalização. In G. Arbix \& M. Zilbovicius (Orgs.). De JK a FHC: a reinvenção dos carros. São Paulo: Scritta.
Powell, W. W.,

Koput, K. W., \&

Smith-Doerr, L. (1996).

Interorganizational collaboration and the locus of innovation: networks of learning in biotechnology. Administrative Science Quarterly, 41, 116-145.

Previtalli, F. S. (2000).

Reestruturação produtiva e novas relações interfirmas na cadeia automobilística nos anos 90. Produto \& Produção, 4(3), 62-76.

Rachid, A. (2000).

Relações entre grandes e pequenas empresas de autopeças - um estudo sobre a difusão de práticas de organização da produção. Tese de doutorado, Universidade Estadual de Campinas, Campinas, SP, Brasil.

Salerno, M. S.,

Marx, R., \&

Zilbovicius, M. (2003).

A nova configuração da cadeia de fornecimento na indústria automobilística do Brasil. Revista de Administração da USP, 38(3), 192-204.

Tan, K. C. (2002).

Supply chain management: practices, concerns, and performance issues. The Journal of Supply Chain Management, 38(1), 42-53.

Thomke, S., \&

Fujimoto, T. (1999).

Front-loading problem solving: implications for development performance and capability. Proceedings of the Technology \& Innovation Management: Conference on Management of Engineering and Technology, Portland, Oregon, U.S.A. 
Yin, R. K. (1989).

Case study research: design and methods. Newbury Park: Sage publications. 